\section{A funcionalidade e incapacidade na velhice: ficar ou não ficar quieto}

\author{
Functionality and disability in old age: \\ to stay still or not to stay still
}

\author{
Funcionalidad y discapacidad en la vejez: \\ moverse o no moverse
}

\author{
${ }^{1}$ Centro de Pesquisas René \\ Rachou, Fundação Oswaldo \\ Cruz, Belo Horizonte, Brasil. \\ 2 Prefeitura Municipal \\ de Belo Horizonte, Belo \\ Horizonte, Brasil. \\ Correspondência \\ J. K. Pereira \\ Av. Lisboa 639 \\ Governador Valadares, $M G$ \\ 35057-450, Brasil. \\ josikatherine@yahoo.com.br
}

\begin{abstract}
The goals of this study were to identify how community-dwelling elderly deal with the prospect of disability/functionality and to understand how the sociocultural context modulates this process. The study adopted a qualitative approach in which the signs, meanings, and actions model was used in the data collection and analysis. The study interviewed 57 elders ranging from 61 to 96 years of age and enrolled in the six primary health units in Bambuí, Minas Gerais State, Brazil. "To stay still or not to stay still" is the underlying question in functioning and disability in old age. However, staying still is not a matter of individual choice, because the answer depends on the elder's financial, intellectual, and subjective resources and available social support. Staying still also implies a concept of old age inexorably associated with disability, leaving the elderly resigned to their condition; when difficulties increase, their only choice is to "wait for death". Health teams need to interfere in this concept, providing care to older people during their recovery and until the end of life.
\end{abstract}

Aged; Health of the Elderly; Anthropology
Josianne Katherine Pereira 1

Karla Cristina Giacomin 2

Josélia Oliveira Araújo Firmo 1

\section{Resumo}

O objetivo deste trabalho é investigar como idosos residentes na comunidade de Bambuí, Minas Gerais, Brasil, lidam com a perspectiva da incapacidadelfuncionalidade na velhice, bem como compreender de que forma o contexto sociocultural modula esse processo. Trata-se de abordagem qualitativa, na qual o modelo de signos, significados e ações foi utilizado na coleta e análise dos dados. Foram entrevistados 57 idosos com idades entre 61 e 96 anos, cadastrados nas seis unidades básicas de saúde de Bambuí. "Ficar ou não ficar quieto" é a dúvida que subjaz ao processo de funcionalidade e incapacidade na velhice; todavia, não se trata de uma questão de escolha individual, pois a resposta depende dos recursos financeiros, intelectuais, subjetivos e de apoio social disponível. Além disso, ficar quieto reflete uma concepção de velhice inexoravelmente associada à incapacidade, deixando os idosos conformados com sua condição, de modo que, quando as dificuldades aumentam, resta-lhes somente "esperar a morte chegar". As equipes de saúde precisam interferir nessa concepção, oferecendo cuidado aos idosos na sua recuperação até o fim da vida.

Idoso; Saúde do Idoso; Antropologia 


\section{Introdução}

Em um contexto de envelhecimento populacional, enquanto a funcionalidade se torna uma preocupação maior da saúde pública, a capacidade funcional é um importante balizador para o desenvolvimento de políticas 1 . Esta dimensão funcional da saúde, amplamente investigada na perspectiva biomédica 1,2 , refere-se à funcionalidade-incapacidade e não se restringe aos aspectos biológicos, pois carrega dimensões simbólicas, sociais e culturais que precisam ser conhecidas.

Nessa perspectiva, ao estudar a interação saúde-doença-incapacidade, o modelo biomédico de compreensão desse processo é apenas uma das maneiras de interpretar esse fenômeno, o qual também é social e culturalmente construído ${ }^{3}$. Eisenberg 4 diferencia a "doença processo" (disease) - que se refere às anormalidades dos processos biológicos e psicológicos, na função e/ou estrutura dos órgãos e sistemas do corpo - e a "doença experiência", que representa a experiência subjetiva de mal-estar. Kleinman ${ }^{3}$ desenvolveu o conceito de "modelos explicativos" (explanatory models) para descrever o conjunto de crenças e expectativas sobre uma doença, formuladas por indivíduos em uma determinada cultura.

Da mesma maneira, a experiência da funcionalidade-incapacidade é culturalmente construída, segundo o contexto onde acontece, o qual confere inteligibilidade a situações e acontecimentos da vida, estruturando o campo social em um tecido semântico 5,6. Quanto à incapacidade funcional, objeto deste trabalho, dois modelos teóricos distintos se destacam 7 . O modelo biomédico define um corpo com impedimentos como aquele que deve ser objeto de intervenção pela medicina, sendo as deficiências classificadas conforme as descrições das lesões, das doenças e compreendidas como desvantagens naturais e indesejadas. O modelo social da deficiência busca a garantia da igualdade entre pessoas com e sem impedimentos corporais, em termos não apenas de oferta de bens e serviços biomédicos, mas também como uma questão de direitos humanos 8 .

À semelhança da questão racial, geracional ou de gênero, a dimensão funcional da saúde reflete as experiências de interação social e do nível de acessibilidade de uma sociedade: quanto maiores as barreiras sociais, maiores também serão as dificuldades de participação impostas àqueles com alguma deficiência corporal 7 e/ou doença. Assim, contextos culturais afetam a inclusão e participação social dos sujeitos com incapacidade 7, ao mesmo tempo que revelam ideologias,

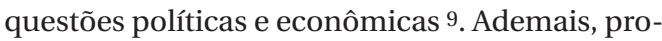
gramas de cuidado à pessoa que envelhece serão mais efetivos caso respondam às necessidades percebidas pelos idosos 2,7. Portanto, estudos antropológicos que abordem as questões socioculturais relacionadas ao envelhecimento e à funcionalidade-incapacidade podem contribuir para ampliar a visão dos serviços de saúde quanto ao significado da experiência da incapacidade e de suas formas de enfrentamento.

Corin et al. 10 desenvolveram um modelo semântico-pragmático que objetiva conjugar a perspectiva interpretativa, influenciada pela tradição hermenêutica, com a teoria crítica. Apesar das diferenças, ambas utilizam abordagens transculturais para descobrir a relatividade dos conceitos e teorias que ajudam a "ampliar" o conceito de realidade, reconhecendo a cultura como uma realidade dinâmica que permeia o indivíduo e que não pode ser expressa como simples variável a ser estudada com variáveis estatísticas 11 .

O modelo proposto por Corin et al. 10, chamado "Signos, Significados e Ações", avalia a problemática por meio de três níveis de análise: (a) estudo do saber, focalizando a atenção sobre as narrativas daqueles que representam a população que se deseja estudar; neste primeiro nível, procura-se identificar a semiologia, os signos, os sinais, os indicadores com base nos quais os diferentes aspectos de saúde e doença são percebidos na comunidade; (b) análise do sistema de interpretação; (c) neste terceiro nível de análise, chamado sistema de ação, visa-se a entender as respostas, as reações, a fim de procurar soluções para os problemas. Em adição, na tentativa de superar os perigos de uma análise do sujeito na microrrealidade, esse modelo considera também os fatores macrossociais, situando-nos em uma dimensão do coletivo. Para tanto, a reconstrução de casos individuais é complementada por uma análise do espaço social, avaliando-se a interação entre histórias e casos individuais, de um lado, e processos coletivos, de outro 6 .

No presente trabalho, valendo-se da perspectiva êmica 6 , na qual a interpretação do cientista é construída a partir da percepção dos entrevistados, e não como uma discussão na visão do pesquisado ou da literatura 12, busca-se investigar como idosos residentes na comunidade de Bambuí lidam com a perspectiva da incapacidade funcional/funcionalidade na velhice. Objetivase, ainda, compreender de que forma o contexto sociocultural modula esse processo. 


\section{Percurso metodológico}

Esta pesquisa qualitativa foi realizada na cidade de Bambuí, Minas Gerais, Brasil, atualmente com aproximadamente 23 mil habitantes. À semelhança do Brasil, o município passa por progressiva urbanização e acelerado envelhecimento: em 1950, sua população rural representava $84 \%$ da população total, reduzindo-se para apenas 15\% em 2010. Quanto ao envelhecimento, em 1960, 3,8\% dos seus habitantes tinham 60 ou mais anos de idade, aumentando para 15,9\% em 2010 (Instituto Brasileiro de Geografia e Estatística. Dados gerais e informações estatísticas da cidade de Bambuí. http://www.ibge.gov.br/cidadesat/ topwindow.htm? 1, acessado em 04/Out/2011). A principal fonte de renda provém de atividades agrícolas, pecuária e de extração mineral, porém um terço da sua população encontra-se em estado de pobreza, sendo elegível para o Programa Bolsa Família 13.

No cuidado à saúde, Bambuí se destacou como centro de profilaxia contra a doença de Chagas com o Posto Avançado de Estudos Emmanuel Dias. A rede pública de assistência à saúde da cidade conta com seis unidades básicas de saúde (UBS), com suas respectivas equipes, que integram a Estratégia Saúde da Família (ESF); um centro de saúde; um Núcleo de Apoio à Saúde da Família (NASF); dois hospitais, um municipal e outro estadual. Inexistem instituições de longa permanência para idosos (Prefeitura Municipal de Bambuí. http://www. bambui.mg.gov.br/portal/htdocs/modules/ mastop_publish/?tac+Dados_gerais, acessado em 04/Out/2011).

Solicitou-se que cada equipe de saúde das seis UBS indicasse pessoas idosas que apresentassem diferentes níveis funcionais: nenhuma, alguma ou completa dificuldade para realizar atividades rotineiras. Os participantes do estudo, todos com idade mínima de 60 anos e em condições de responder a perguntas, residiam na sede do município, estando cadastrados em UBS da cidade. Os critérios de inclusão visaram a garantir a heterogeneidade dos participantes e a multivocalidade, segundo o território da UBS, o gênero, a idade e a condição funcional. O critério de saturação regulou o número de entrevistas 14 .

Este trabalho integra o projeto Abordagem Antropológica da Dinâmica da Funcionalidade em Idosos, aprovado pelo Comitê de Ética do Centro de Pesquisas René Rachou, Fundação Oswaldo Cruz (CAAE: 0028.0.245.000-9). As entrevistas foram realizadas mediante consentimento livre e esclarecido dos idosos.

\section{Coleta dos dados}

Na presente pesquisa, o modelo de "Signos, Significados e Ações”, desenvolvido por Corin et al. 10 , foi utilizado na coleta e análise dos dados, para permitir a sistematização dos elementos do contexto que participam da construção de maneiras típicas de pensar e agir diante da funcionalidade e do enfrentamento da incapacidade. Nesse modelo, as entrevistas devem ser iniciadas com perguntas que revelam ações em face do evento a ser investigado, uma vez que, diante deste, o comportamento pode explicar melhor a influência dos valores socioculturais daquele local 10 .

Para reconstruir o universo de representações (maneiras de pensar) e comportamentos (maneiras de agir) associados a esses processos pelos idosos residentes em Bambuí, foram realizadas entrevistas no domicílio, guiadas por um roteiro semiestruturado. As perguntas geradoras foram: (a) Como você acha que está sua saúde? (b) Para você, o que é uma saúde boa? E saúde ruim? (c) Como é o seu dia a dia, sua rotina? Como é um dia em sua vida? (d) Qual(ais) o(s) conselho(s) você daria para chegar à sua idade com boa saú$d e$ ? As primeiras perguntas foram direcionadas às questões de saúde e doença porque o construto funcionalidade-incapacidade é parte da percepção de saúde dos idosos acerca do processo saúde-doença, conforme verificado em outra pesquisa antropológica realizada nessa mesma localidade 15 .

Com base nas respostas obtidas, outras perguntas foram feitas abordando o contexto biopsicossocial, os recursos, as dimensões relacionadas à funcionalidade e o impacto da incapacidade. As entrevistas foram gravadas para possibilitar a análise mais cuidadosa e detalhada dos dados.

\section{Análise dos dados}

Primeiramente, as entrevistas foram transcritas e lidas várias vezes. Nesse momento, algumas frases, palavras, adjetivos, concatenação de idéias, sentido geral do texto, foram destacados. O processo de análise buscou identificar os sistemas de signos, significados e ações, ou seja: (a) os diferentes tipos de signos associados aos fenômenos investigados - velhice, funcionalidade e incapacidade funcional - e ao cuidado à saúde; (b) as explicações privilegiadas em face desses signos; (c) as reações e ações que eles desencadeiam 12. Posteriormente, as articulações entre os sistemas de signos, significados e ações foram examinadas, avaliando-se os diferentes elementos do contexto pessoal, social e cultural acerca da construção e evolução das reações e dos 
comportamentos diante da condição funcional na velhice 12 .

Para assegurar o anonimato dos entrevistados, eles foram identificados por sexo, número da entrevista, idade e estado civil. A primeira mulher entrevistada, por exemplo, foi identificada como mulher 1 (M1, 70 anos, estado civil); a segunda, mulher 2 (M2, 87 anos, estado civil) e assim sucessivamente.

\section{Resultados e discussão}

Foram entrevistados 57 idosos, 27 homens e 30 mulheres, com idades entre 60 e 96 anos, cadastrados nas seis UBS da cidade de Bambuí. Esse número de entrevistas - maior do que o habitualmente observado em pesquisas qualitativas - pode ser explicado pela necessidade de se prosseguir até que todas as questões atingissem a saturação. No grupo, predominavam a religião católica e a baixa escolaridade, visto que apenas três entrevistadas tinham mais de oito anos de escolaridade. Muitos relataram vivências difíceis na infância e vida adulta em razão de precariedade e origem rural, tendo como principais motivos para a mudança para a cidade o maior acesso a educação e trabalho para os filhos, a busca por melhores condições de vida e a proximidade do serviço de saúde.

No grupo pesquisado, os signos relativos à dinâmica da funcionalidade foram: "dar conta", "não dar conta" e "dar trabalho", cujos significados remetiam, respectivamente, à experiência da funcionalidade, da incapacidade e da dependência de terceiros. A maior parte dos entrevistados referiu sua saúde como boa, construto que se relaciona à capacidade funcional e à autonomia, sugerindo que a questão da funcionalidade-incapacidade parece modular como esses idosos agem na velhice. A vivência da incapacidade influi na avaliação que os idosos fazem sobre a sua saúde: quanto mais grave a incapacidade, pior a avaliação da saúde. Com base nesses resultados, fez-se o aprofundamento analítico da questão das ações, ou seja, os modos de agir diante da perspectiva de alguma dificuldade na realização de tarefas diárias. Logo, no presente trabalho, as formas como os idosos lidavam com a experiência real ou com a perspectiva de uma incapacidade eram "ficar quieto" e "não ficar quieto". Essa dúvida, "ficar ou não ficar quieto", fundamentase na visão da velhice como tragédia, difundida na população estudada.

\section{A velhice como tragédia}

Perguntado sobre o que a idade trouxe para sua vida, este idoso é categórico: "Só tragédia, né (risos). A idade só traz ruindade. As coisas que tem vontade de fazer, não faz mais: ir pro forró. (...) Graças a Deus, (...), só o que eu tô reclamando é da idade, né. Tá puxado” (H23, 82 anos, casado).

Outro homem é contundente: "Só o que não tá bom é a velhice. Porque a velhice é doentia. Há um ditado que fala assim: senectus esculopus: a velhice é doentia. Eé" (H15, 79 anos, casado).

O ditado latino senectus ipsa morbus est tem como tradução "a velhice é, ela mesma, uma doença”. Essa visão milenar da velhice como inexorável tragédia pessoal, irreversível e irremediável 16 participa do imaginário da velhice na cultura ocidental.

Na percepção dos idosos entrevistados, o signo "quietar" representa admitir que se está velho, e seu efeito presumido - "se quietar, dá uma velhice" - indica a mesma concepção da velhice como doença. Ademais, um corpo quieto, inerte, imóvel alude à ideia de um corpo morto. Assim, "quietar-se" também prenuncia a própria finitude; é o lembrete da precariedade e fragilidade humanas 17 .

Segundo Le Breton 17, o problema da velhice é que esta sempre vem acompanhada da ideia da morte e da precariedade da condição humana: a pessoa idosa encarna o envelhecimento e a morte - os inomináveis da modernidade. $\mathrm{O}$ velho está reduzido ao seu corpo, sua singularidade, quem ele foi, o que construiu, e toda a sua trajetória de vida está apagada sob a ótica equivocada do corpo danificado, que precisa ser alimentado, ser cuidado; o idoso passa a ser objeto de seu corpo e não mais o sujeito. Em síntese, a velhice representa o instante em que o corpo se mostra ao olhar do outro como não sendo mais favorável ${ }^{17}$. Desse modo, em uma perspectiva dialética, a experiência corporal do envelhecimento se transforma em uma experiência social, reforçada pela ciência biológica como uma degeneração orgânica irreversível e irremediável, fadada ao declínio das funções e das reservas fisiológicas e à morte 17 .

Barros 18 descreve que, no imaginário social brasileiro, ser velho sempre foi algo associado a perdas, limitações físicas e dos papéis sociais, dependência, sofrimento, doenças e a morte. Um estudo 19 realizado na cidade de Campinas, São Paulo, observou que os idosos daquela cidade, de maior porte, concebem a velhice como perda ou incapacidade, sendo as enfermidades consideradas como distúrbios próprios da idade e sem tratamento. De forma similar, para os idosos bambuienses, a velhice é percebida como 
uma doença progressiva e incapacitante, na qual a perda não é apenas um conceito abstrato, mas uma realidade: o corpo e a vida mudaram, uns pararam de trabalhar, outros de cozinhar, outros ainda de se divertir, visitar amigos e familiares. A entrevistada com maior idade do grupo narra seu momento de vida: "Muita idade... Não dou conta mais, quietei mesmo... na minha saúde, eu ficava sozinha, trabalhava sozinha... foi acabando e acho que ficou desse jeito" (M16, 96 anos, viúva).

Essa visão fatalista da velhice aparece ainda mais forte entre aqueles que foram menos favorecidos do ponto de vista socioeconômico ao longo de toda a vida e continuam a sê-lo na velhice. Uma mulher refere-se ao tempo de infância: “(...) Aqui, os pobres que nem eu, andava na rua pedindo. (...) a gente não podia comprar nem $1 \mathrm{~kg}$ de carne para comer, mas a gente tinha saúde, tava boa. Vestia uma roupa usada que os outros davam, mas não tava sentindo nada. Agora, hoje, você pode ter tudo, mas tá doente, não adianta não" (M24, 86 anos, viúva).

Nesse contexto, cabe discutir o que seria escolha individual sobre a vida e o que, ao longo desta, reflete falta de opções. van Kampen et al. 20 , em artigo de revisão, buscaram elucidar a relação entre incapacidade funcional e pobreza, porém, se a incapacidade conduz à pobreza, sofre influência da cultura e depende fortemente dos valores sociais existentes na sociedade estudada. Pessoas com alguma dificuldade, ao serem consideradas incapazes e sofrerem algum tipo de estigma, podem ser mais vulneráveis à pobreza. Outra possível relação entre incapacidade e pobreza seria esta última como causa da dificuldade. Mais uma explicação plausível poderia ser a existência de possíveis barreiras físicas que reforçariam a incapacidade. Nesse caso, a pobreza dificultaria o acesso à alimentação, aos serviços de saúde, ao transporte, à mobilidade dentro e fora de casa, quadro que pode piorar a condição das doenças e favorecer o aparecimento da incapacidade, resultando em mais pobreza, mais estigma, que, por sua vez, levariam a mais incapacidade. Para quebrar esse círculo vicioso, seria necessário, além de conhecer os fatores determinantes e agravantes da incapacidade, reduzir o estigma, coibir as práticas discriminatórias e fortalecer o empowerment dos indivíduos com dificuldades. Ou seja, as intervenções deverão operar na direção dos direitos humanos e na compreensão da incapacidade como um fenômeno sociocultural, e não apenas como uma fatalidade biológica 7,20.

O modelo biomédico apregoa que quem cuida da saúde, pratica exercícios, alimenta-se bem e consulta regularmente um médico tem maior chance de viver mais e melhor 21 . No entanto, esse modelo parece ignorar que o "estilo de vida" do sujeito, muitas vezes, é o único modo possível de sobrevivência dentro de determinado contexto social 22. Essa responsabilização do idoso por sua própria vida encontra-se bastante difundida entre os profissionais da saúde e desresponsabiliza outros atores, como a família, a sociedade e o poder público, fenômeno que Debert 23 denominou "reprivatização da velhice".

No grupo pesquisado, as pessoas idosas se consideravam responsáveis pela sua condição de vida, de trabalho, e pelos resultados disso na velhice. É o que pode ser observado no relato abaixo: "Eu fiquei nas condições que eu tô aqui agora por ignorância minha mesmo. No tempo que eu era novo, tinha saúde, graças a Deus, o peso que era pra dois eu queria pegar sozinho e muitas das vezes eu peguei" (H7, 84 anos, casado).

Na contemporaneidade, de acordo com Giddens 24 , a noção de estilo de vida é crucial para compreender o momento da velhice, pois a reprodução social de uma forma de viver e pensar se faz por meio dos processos de vigilância somados à reflexividade, e quem não faz parte desse sistema de reprodução social torna-se alheio e isolado. Portanto, a velhice e a loucura são exemplos de condições que, segundo o pensamento moderno, teriam sido criadas pelo próprio indivíduo. Entretanto, como as condições de vida dependem das possibilidades de acesso e aquisição de recursos, esses modelos lineares de causalidade merecem ser questionados 24 .

Outro homem mostra-se resignado diante de "uma vida cheia de sofrimentos e peripécias": "Eu costumo falar o seguinte, é, o Brasil é campeão em muita coisa: futebol, carnaval e acidente de trabalho. Eu também, eu ajudei a conquistar a taça deste triste campeonato. Quando tinha 14 anos, eu fui acidentado no trabalho, perdi o braço esquerdo, fui amputado e agora é, é, é uma vida cheia de sofrimentos, de peripécias. Eu tinha 14 anos, fui aprender a trabalhar com uma mão só, agora, depois de setenta e tantos anos, veio o AVC e me pegou o lado direito, o lado bom [risos] (...) ...mas eu tô aí, não posso me queixar não. Se eu perdi... porque eu tenho mais que agradecer a Deus de eu já viver mais de que a média brasileira, apesar da luta difícil na vida. Porque eu sou de origem muito difícil na vida" (H49, 77 anos, casado).

Boltanski 25, ao estudar a "cultura somática" nas diferentes classes de trabalhadores, evidenciou que o nível de instrução média de um grupo influencia na forma como este presta atenção ao próprio corpo. À medida que se sobe na hierarquia social e no nível de instrução formal, decresce o trabalho físico exaustivo e aumenta o intelectual. Dessa forma, é possível manter-se uma relação mais consciente com o corpo, uma vez que trabalhos extenuantes fisicamente dificul- 
tam a comunicação entre o sujeito e seu corpo. Além disso, caso sinta algo, terá de interromper a atividade, o que faz o trabalhador ter medo de perder seu meio de sobrevivência. Por sua vez, ao trabalhar de modo insalubre, sofre acidentes, doenças profissionais e outros agravos, que podem comprometer as condições de vida na velhice.

Ao discutir a questão do curso da vida na contemporaneidade, Debert 26 problematiza a questão da liberdade de escolha e enfatiza que, embora o curso de vida seja uma construção social e cultural, não se trata de algo que o homem possa fazer e refazer, como se não houvesse limites - impostos pela sociedade à qual pertence - à sua criatividade e à sua capacidade de inscrever a cultura na natureza. Para Debert 26, é necessário reconhecer que, se a responsabilidade individual pela escolha é democraticamente distribuída, os meios para agir em conformidade com essa responsabilidade não o são. Caso contrário, o descaso de alguns setores do poder público e da sociedade pareceria justificado ante idosos que enfrentam o declínio inevitável do corpo, que não responde às vontades individuais, por serem os velhos considerados consumidores falhos. De modo similar, aqueles cujo corpo é compreendido como resultado de transgressões também não teriam direito à piedade ${ }^{24}$. Segundo Bauman 27, a liberdade de escolha é uma condição graduada, que, somada à desigualdade das condições sociais e ao dever da liberdade sem os recursos que permitam uma escolha mais livre, parece ser a fórmula exata para uma vida sem dignidade, carregada de humilhação e autodepreciação.

Logo, para que os idosos entrevistados mudem a concepção cultural da velhice como uma fase negativa para uma que possa trazer recompensas 28 , eles terão de vislumbrar novas formas de viver esse momento. Para isso, devem ser-lhes oferecidas condições para enfrentar as dificuldades e minimizar as perdas que marcam a forma como eles conhecem a velhice e se reconhecem nela.

\section{- "Ficar ou não ficar quieto"}

Tendo como pano de fundo essa perspectiva da velhice como tragédia, observa-se uma dualidade, quase hamletiana em face do processo funcionalidade-incapacidade. Emergiram da análise duas maneiras, em princípio antagônicas, de lidar com a incapacidade, refletidas na categoria: "ficar ou não ficar quieto". Os signos "não pode parar", "não fico parado", "não pode quietar" e "movimentar" aparecem em contraposição a "velho fica mais quieto", "parei de fazer", "esperar Deus", "tenho de esperar, não posso me matar". Contudo, as ações referentes à questão "ficar ou não ficar quieto" indicam que as maneiras de agir diante da incapacidade não são apenas escolhas, mas se relacionam ao cuidado à saúde e ao contexto sociocultural, como se verá a seguir.

\section{- "Velho não pode parar"}

Considerando-se cada UBS separadamente, verificou-se que, naquela em que era atendida a população com melhores condições socioeconômicas, os idosos, inclusive aqueles que relatavam doenças incapacitantes, apresentavam-se com discurso mais positivo e menos queixoso em relação à velhice, segundo o qual "velho não pode parar". Portadora de retinose pigmentar, doença responsável pela cegueira total de um olho e parcial do outro, uma idosa de maior poder aquisitivo, que administrava sua própria construtora de imóveis, não se mostrava preocupada com eventuais barreiras físicas, nem se queixava de problemas de saúde; sentia-se privilegiada por sua vida e, apesar de morar sozinha, contava com apoio de familiares e de vizinhos: “...minha saúde eu acredito que é boa, entendeu. Também não fico parada... Porque a única coisa ruim que eu acredito que eu tenho é só a visão. Também Deus não pode dar tudo pra uma pessoa só... Minhas filhas são todas boazinhas comigo... Qualquer coisa que acontecer a gente se vira... a gente já guarda as reservas [dinheiro] da gente pra isso..." (M44, 69 anos, divorciada).

Os idosos desta UBS tinham maior poder aquisitivo, maior nível de escolaridade próprio ou de familiares e contavam com cuidadores, planos privados de saúde, pouco utilizando os serviços de saúde pública. Concepção semelhante foi observada nos demais territórios, entre pessoas mais novas, com pouca ou nenhuma dificuldade nas funções diárias, maiores recursos financeiros, intelectuais e/ou apoio social. Um idoso bambuiense, que trabalhou como bancário em Belo Horizonte e retornou para Bambuí na sua aposentadoria, declara-se adaptado à nova fase: "Aí morando aqui, com o tempo a gente aprendeu a viver com o que tinha aqui (...) Tenho bastante amigo. Nós temos movimento de igreja. Eu, por exemplo, pertenço ao encontro de casais da igreja, eu sou Vicentino, então tem muita atividade. Eu sou aposentado, mas eu não tenho tempo pra nada (...) Eu pesco, eu sou criador de pássaro registrado no IBAMA (...) Comigo não tem esse negócio de ociosidade... Tenho nada não [problemas de saúde]" (H18, 65 anos, casado).

Sendo assim, a maneira de lidar com a velhice e a funcionalidade, de acordo com os achados deste trabalho, pode variar conforme a disponibilidade de recursos financeiros, intelectuais, subjetivos e ou de apoio social, os quais parecem 
mediar a forma como idosos experimentam a velhice com ou sem limitações. Possivelmente, outras condições, como as questões psicológicas, também interfiram no modo como essas pessoas constroem a subjetivação desses eventos de vida e as suas velhices 16 .

\section{- "Velho fica mais quieto"}

Nos territórios de maior risco sociossanitário, os idosos têm discurso mais negativo acerca de suas vidas e da velhice, principalmente aqueles de maior faixa etária, mais adoentados, mais dependentes dos serviços públicos, com maiores dificuldades diárias e menos recursos disponíveis - financeiros, intelectuais, subjetivos e de apoio social. Para estes entrevistados, a maneira de lidar com a funcionalidade é oposta a "velho não pode parar", sendo representada pelo signo "velho fica mais quieto", que externa certo conformismo com as limitações que surgiram com o aumento da idade, como afirma este homem: “ $A$ idade bota as coisas tudo mais custoso pra gente né... o peso da idade... É muita coisa que a gente vai deixando... Então, mas também não tem [outro jeito], como diz o outro, tô conformado" (H30, 76 anos, solteiro).

A mesma concepção de que não há nada a fazer, a não ser aquietar-se e se conformar, é transmitida a um idoso ao procurar o profissional de saúde: “(...) [o médico] só falou comigo assim: 'o senhor não preocupa muito não, caça um jeito de ficar mais despreocupado, repouso, isso maior que você sente agora é idade. Essa idade da gente aparece uma coisinha aqui, aparece outra por lá, o senhor não tem que preocupar, não'” (H7, 84 anos, casado).

Contudo, esta concepção revela-se uma faca de dois gumes: por um lado, aquietar-se poderia favorecer a resiliência de pessoas com limitações; por outro, mostra-se uma estratégia ineficaz e contraproducente de cuidado ${ }^{2}$, a qual, possivelmente, torná-los-á ainda mais dependentes e desamparados no futuro.

Portanto, com o agravamento da condição de saúde e da incapacidade, quando as dificuldades aumentam a ponto de lhes impedir uma vida digna e independente, os idosos que ficam mais quietos desenvolvem uma segunda forma de pensar e agir: "esperar Deus" ou "esperar a morte chegar". Nesse momento, viver perde o sentido e nada mais há a fazer, como ilustram os dois relatos a seguir. No primeiro, uma idosa restrita ao leito por obesidade mórbida, cujo único gesto independente é abrir e fechar uma janela com uma bengala, necessitando de cuidados para todas as atividades cotidianas, sem filhos morando na cidade, admite: "Tem de dar conta de aguentar até Ele [Deus] me levar. Vontade de ir para o céu... Criei duas [filhas] e nenhuma está aqui..." (M34, 81 anos, viúva).

A segunda idosa, tendo sofrido "derrame" e interrompido o tratamento fisioterapêutico por dificuldades de transporte até a clínica conveniada com a prefeitura, explica: “...mas fazer o quê, eu não posso me matar... tenho que esperar Deus... consulto diariamente porque não sara, mas a gente fica naquela fé que vai sarar, mas o médico ótimo me desanimou que isso é idade, que eu tenho que aceitar... Meu filho mora longe, quer que eu vou morar lá, mas não posso, aqui é minha casa..." (M24, 86 anos, viúva).

Observa-se, assim, que, no caso dos entrevistados mais incapacitados, a desistência da vida vinha acompanhada da percepção da ausência de apoio social, principalmente da família, único recurso reconhecido pelos idosos: "Que minha família mora tudo longe né. Aqui no Bambuí, só eu... Eu sou igual filhote de perdiz, sou só eu" (M13, 69 anos, união estável).

Novamente, a questão da velhice com dificuldades e sem apoio é o que permeia essa maneira de agir dos idosos entrevistados. Se antes, para eles, a velhice era vivida e percebida como perdas, agora ela também é vivida diariamente diante da perspectiva da morte, constructos associados no imaginário social 17,29 . Não se pode negar que os idosos morrem, mas também não se pode negar que as crianças morrem, os jovens morrem, os adultos morrem, pois a morte não é uma condição da velhice, é uma condição da vida 19. Porém, a morte do indivíduo não se limita à morte biológica, existe a morte social, que ocorre quando ele não se reconhece como a mesma pessoa, por não conseguir executar as atividades que fazia anteriormente, podendo afetar toda a dinâmica familiar ${ }^{18}$. Ademais, a morte dos vínculos sociais precede a morte física e, nesse momento, a religião, a fé e Deus aparecem para esses indivíduos como âncoras a que se agarram quando a vida pouco parece ter para lhes oferecer 30 . Nesse contexto, "ficar ou não ficar quieto" e "esperar Deus" podem não ser escolhas individuais, mas o resultado concreto do investimento familiar e coletivo - ou da falta dele - tanto na possibilidade de melhora das pessoas idosas com incapacidade, quanto na velhice digna.

\section{Considerações finais}

A velhice é uma experiência inédita para cada indivíduo, com dimensões simbólicas, sociais e culturais. Acreditar que todos poderão viver da mesma forma é deixar de compreender que a velhice, em seu processo, apresenta inúmeras 
formas de ser vivida, dependendo dos caminhos escolhidos e dos determinantes desse envelhecimento. Entretanto, percebe-se que, em Bambuí, os fatores que medeiam as várias formas de viver a velhice com ou sem saúde e com ou sem dificuldades nas funções diárias são os recursos financeiros, intelectuais, subjetivos e sociais. Para idosos com mais recursos, a incapacidade e a velhice não são condições vividas necessariamente com sofrimento e desesperança. Para os demais, a velhice com dificuldades nas atividades diárias vem acompanhada de conformismo e da concepção de ser uma fase associada a perdas, a restrições e à morte.

A concepção cultural vigente considera que deixar de fazer algo ao envelhecer é normal. Dessa forma, os serviços públicos sociais e de saúde não devem esperar que os idosos demandem cuidados para uma incapacidade, pois, na visão daqueles, não haveria recursos ou tratamento para suas limitações: "isso é coisa da idade”. Em adição, os idosos se ressentem da falta de intervenção proativa e efetiva de políticas públicas inclusivas, para que não evoluam para uma con- dição pior. A presença dos profissionais da ESF e do NASF pode ser um alento, mas ainda não foi reconhecida pelos entrevistados. Para aqueles que já experimentam a incapacidade com dependência, urge a implementação de políticas públicas que ampliem a possibilidade de apoio à família, pela sociedade e pelos serviços públicos sociais e de saúde, que os alcancem onde estiverem, no domicílio, em hospitais ou instituições.

Essa concepção cultural, que vê a incapacidade funcional como condição inexorável da velhice e responsabilidade exclusiva de quem a vivencia, desresponsabiliza o Estado e a sociedade de seu dever constitucional e ético de amparar pessoas idosas em situação de vulnerabilidade. Ainda que os resultados não permitam generalização, compreender a percepção dos próprios idosos acerca da dimensão funcional da saúde é parte de um cuidado mais humanizado e efetivo dessa população. Afinal, a avaliação da funcionalidade e a reabilitação da incapacidade funcional devem ser parte do cuidado de pessoas de todas as idades, sendo incluídas no cotidiano dos profissionais de saúde.

\section{Resumen}

El objetivo de este trabajo es investigar cómo los ancianos residentes en la comunidad se ocupan de la perspectiva de la funcionalidad/discapacidad en la vejez, así como entender de qué forma el contexto sociocultural modula este proceso. Se trata de un abordaje cualitativo, en el cual el modelo de signos, significados y acciones se utilizó en la reunión y análisis de los datos. Se entrevistaron a 57 ancianos con edades entre 61 y 96 años, registrados en las Unidades Básicas de Salud en Bambuí, Minas Gerais, Brasil. "Moverse o no moverse" es la cuestión que subyace a la movilidad y discapacidad en el proceso de la vejez. Sin embargo, no es una cuestión de elección individual, porque la respuesta depende de los recursos de apoyo financiero, intelectuales, subjetivos y sociales disponibles. Además, no moverse (estarse quieto) refleja una concepción de la vejez inexorablemente asociada a la discapacidad, que deja a las personas de edad conformándose con su condición física y cuando las dificultades aumentan, ellos sólo "esperan la llegada de la muerte". Los equipos de salud tienen que intervenir para prevenir esta concepción sobre la condición física en la tercera edad.

\section{Colaboradores}

J. K. Pereira, K. C. Giacomin e J. O. A. Firmo contribuíram na redação e revisão do artigo.

\section{Agradecimentos}

Ao Centro de Pesquisas René Rachou, Fundação Oswaldo Cruz, à FAPEMIG e aos idosos que participaram da pesquisa. 


\section{Referências}

1. House JS. Understanding social factors and inequalities in health: 20th century progress and 21st century prospects. J Health Soc Behav 2002; 43:125-42.

2. Vincent C, Deaudelin I, Robichaud L, Rousseau J, Viscogliosi C, Talbot LR, et al. Rehabilitation needs for older adults with stroke living at home: perceptions of four populations. BMC Geriatr 2007; 7:20.

3. Kleiman A. Patients and healers in the context of culture. An exploration of borderland between anthropology and psychiatry. Berkeley/Los Angeles: University of California Press; 1980.

4. Eisenberg L. Disease and illness: distinctions between professional and popular ideas of sickness. Cult Med Psychiatry 1977; 1:9-23.

5. Geertz C. A interpretação das culturas. Rio de Janeiro: Editora Guanabara Koogan; 1989.

6. Uchôa E. Contribuições da antropologia para uma abordagem das questões relativas à saúde do idoso. Cad Saúde Pública 2003; 19:849-53.

7. Diniz D, Barbosa L, Santos WR. Deficiência, direitos humanos, justiça. SUR - Revista Internacional de Direitos Humanos 2009; 6:65-77.

8. Barnes C. Disability activism and the price of success: a British experience. Intersticios: Revista Sociológica de Pensamiento Crítico 2007; 1:1-15.

9. Caprara A. Uma abordagem hermenêutica da relação saúde-doença. Cad Saúde Pública 2003; 19:923-31.

10. Corin E, Uchoa E, Bibeau G, Kouma-Re B. Articulation et variations des systèmes de signes, de sens et d'actions. Psychopathologie Africaine 1992; 24:183-204.

11. Corin E. The culture frame: context and meaning in the construction of health. In: Amick BC, Levine S, Tarlov AR, Walsh DC, editors. Society and health. Oxford: Oxford University Press; 1995. p. 272-304.

12. Uchôa E, Vidal JM. Antropologia médica: elementos conceituais e metodológicos para uma abordagem da saúde e da doença. Cad Saúde Pública 1994; 10:497-504.

13. Rios DFF, Pinto NMA, Loreto MDS, Fiúza ALC. O programa bolsa-família em um contexto de cidades rurais: o caso de Bambuí, MG. Oikos: Revista Brasileira de Economia Doméstica 2011; 22:15070

14. Fontanella BJB, Luchesi BM, Saidel MGB, Ricas J, Turato ER, Melo DG. Amostragem em pesquisas qualitativas: proposta de procedimentos para constatar saturação teórica. Cad Saúde Pública 2011; 27:389-94.

15. Fonseca MGUP, Firmo JOA, Loyola Filho AI, Uchôa E. Role of autonomy in self-assessment of health by the elderly. Rev Saúde Pública 2010; 44:159-65.
16. Beauvoir S. A velhice. $3 \underline{a}$ Ed. Rio de Janeiro: Nova Fronteira; 1990.

17. Le Breton D. Antropologia do corpo e modernidade. Petrópolis: Editora Vozes; 2011.

18. Barros MML. Trajetória dos estudos da velhice no Brasil. Sociologia, Problemas e Práticas 2006; 52:109-32.

19. Garcia MAA, Odoni APC, Souza CS, Frigerio RM, Merlin SS. Idosos em cena: falas fazer adoecer. Interface Comun Saúde Educ 2005; 9:537-52.

20. van Kampen M, van Zijverden IM, Emmett T. Reflections on poverty and disability: a review of literature. Asia Pacific Disability Rehabilitation Journal 2008; 19:19-37.

21. Nelson ME, Blair SN, Duncan PW, Judge JO, King AC, Macera CA, et al. Physical activity and public health in older adults: recommendation from the American College of Sports Medicine and the American Heart Association. Med Sci Sports Exerc 2007; 39:1435-45.

22. Castiel LD. Quem vive mais morre menos? Estilos de risco e promoção de saúde. In: Bagrichevsky M, Palma A, Estevão A, organizadores. A saúde em debate na educação física. Blumenau: Edibes; 2003. p. 79-98.

23. Debert GG. A reinvenção da velhice: socialização e processos de reprivatização do envelhecimento. São Paulo: Edusp; 1999.

24. Giddens A. Modernidade e identidade. Rio de Janeiro: Jorge Zahar Editores; 2002.

25. Boltanski L. As classes sociais e o corpo. 3a Ed. São Paulo: Editora Paz e Terra; 2004.

26. Debert GG. A dissolução da vida adulta e a juventude como valor. Horizontes Antropológicos 2010; 34:49-70.

27. Bauman Z. O mal-estar da pós-modernidade. Rio de Janeiro: Jorge Zahar Editores; 1998.

28. Guerra ACLC, Caldas CP. Dificuldades e recompensas no processo de envelhecimento: a percepção do sujeito idoso. Ciênc Saúde Coletiva 2010; 15:2931-40.

29. Guimarães I, Carneiro MHS. Envelhecimento e finitude: qual a representação da morte? Estud Interdiscip Envelhec 2012; 17:7-18.

30. Santos WJ, Firmo JOA, Giacomin KC, Pereira JK. $\mathrm{O}$ enfrentamento da incapacidade funcional por idosos da comunidade de Bambuí: crença religiosa e descrença nos serviços públicos de saúde. Ciênc Saúde Coletiva 2013; 18:2319-28.

Recebido em 23/Mar/2014

Versão final reapresentada em 04/Dez/2014

Aprovado em 05/Fev/2015 